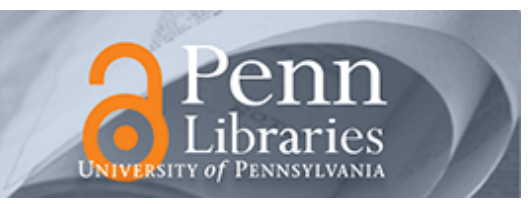

University of Pennsylvania

ScholarlyCommons

7-17-2015

\title{
Predictors of Hospitalization and Quality of Life in Heart Failure: A Model of Comorbidity, Self-Efficacy and Self-Care
}

Harleah G. Buck

Victoria V. Dickson

University of Pennsylvania

Roberta Fida

Barbara Riegel

University of Pennsylvania, briegel@nursing.upenn.edu

Fabio D'Agostino

See next page for additional authors

Follow this and additional works at: https://repository.upenn.edu/nrs

Part of the Behavioral Medicine Commons, Cardiology Commons, Cardiovascular Diseases

Commons, Circulatory and Respiratory Physiology Commons, Medical Humanities Commons, Nursing

Commons, and the Preventive Medicine Commons

\section{Recommended Citation}

Buck, H. G., Dickson, V. V., Fida, R., Riegel, B., D'Agostino, F., Alvaro, R., \& Vellone, E. (2015). Predictors of Hospitalization and Quality of Life in Heart Failure: A Model of Comorbidity, Self-Efficacy and Self-Care. International Journal of Nursing Studies, 52 (11), 1714-1722. http://dx.doi.org/10.1016/ j.ijnurstu.2015.06.018

This paper is posted at ScholarlyCommons. https://repository.upenn.edu/nrs/190

For more information, please contact repository@pobox.upenn.edu. 


\title{
Predictors of Hospitalization and Quality of Life in Heart Failure: A Model of Comorbidity, Self-Efficacy and Self-Care
}

\author{
Abstract \\ Background \\ Comorbidity is associated with decreased confidence or self-efficacy to perform self-care in heart failure \\ patients which, in turn, impairs self-care behaviors. Comorbidity is also associated with increased \\ hospitalization rates and poorer quality of life. Yet the manner in which comorbidity and self-efficacy \\ interact to influence self-care, hospitalization, and quality of life remains unclear. \\ Objectives
}

The purpose of this study was to test an explanatory model. The research questions were (1) What is the contribution of comorbidity to heart failure self-care behaviors and outcomes (i.e. hospitalization, quality of life)? and (2) Is comorbidity a moderator of the relationship between self-efficacy and heart failure selfcare behaviors?

Design

This was an analysis of an existing dataset of 628 symptomatic, older (mean age $=73$, standard deviation $(S D)=11)$ male $(58 \%)$ Italian heart failure patients using structural equation modeling and simple slope analysis.

Results

Higher levels of self-care maintenance were associated with higher quality of life and lower hospitalization rates. Higher levels of comorbidity were associated with lower levels of self-care management. Comorbidity moderated the relationship between self-efficacy and self-care maintenance, but not self-care management. Post hoc simple slopes analysis showed significantly different slope coefficients ( $p$ diff < .05). Specifically, in patients with less comorbidity, the relationship between selfefficacy and self-care was significantly stronger than in patients with higher comorbidity.

\section{Conclusions}

Self-efficacy is important in the self-care maintenance process at each level of comorbidity. Because higher comorbidity weakens the strength of the relationship between self-efficacy and self-care maintenance, tailoring interventions aimed at improving self-efficacy to different levels of comorbidity may be key to impacting hospitalization and quality of life.

\section{Keywords}

comorbidity, self-efficacy, self-care, explanatory model, heart failure

\section{Disciplines}

Behavioral Medicine | Cardiology | Cardiovascular Diseases | Circulatory and Respiratory Physiology | Medical Humanities | Medicine and Health Sciences | Nursing | Preventive Medicine

\section{Author(s)}

Harleah G. Buck, Victoria V. Dickson, Roberta Fida, Barbara Riegel, Fabio D'Agostino, Rosaria Alvaro, and Ercole Vellone 
Title: Predictors of Hospitalization and Quality of Life in Heart Failure: a model of comorbidity, self-efficacy and self-care.

First/Corresponding author: Harleah G. Buck PhD, RN, CHPN, FPCN

Assistant Professor, College of Nursing, Penn State University, 201 Health and Human

Development East, University Park, PA. 16802, USA. Phone: $\underline{814-863-3495}$. Fax: 814-865-3779.

Email: $\underline{\text { hgb2@psu.edu }}$

Victoria Vaughan Dickson, PhD, RN, CRNP, FAHA, FAAN

Assistant Professor, College of Nursing, New York University, New York, NY.

Roberta Fida, PhD

Assistant Professor, Department of Psychology, Sapienza University of Rome, Rome, Italy

Barbara Riegel, PhD, RN, FAAN

Professor, School of Nursing, University of Pennsylvania, Philadelphia, PA

Fabio D'Agostino, PhD, RN

Research Fellow, Department of Biomedicine and Prevention, University of Rome Tor Vergata,

Rome, Italy

Rosaria Alvaro, MSN, RN

Associate Professor, Department of Biomedicine and Prevention, University of Rome Tor Vergata, Rome, Italy

Ercole Vellone, $\mathrm{PhD}, \mathrm{RN}$

Research fellow, Department of Biomedicine and Prevention, University of Rome Tor Vergata, Rome, Italy

\section{Abstract}

Background: Comorbidity is associated with deceased confidence or self-efficacy to perform self-care in heart failure patients which, in turn, impairs self-care behaviors. Comorbidity is also associated with increased hospitalization rates and poorer quality of life. Yet the manner in which comorbidity and self-efficacy interact to influence self-care, hospitalization and quality of life remains unclear.

Objectives: The purpose of this study was to test an explanatory model. The research questions were: 1) What is the contribution of comorbidity to heart failure self-care behaviors and outcomes (i.e. hospitalization, quality of life)? and 2) Is comorbidity a moderator of the relationship between self-efficacy and heart failure self-care behaviors? 
Design: This was an analysis of an existing dataset of 628 symptomatic, older (mean age = $73, \mathrm{SD}=11)$ male $(58 \%)$ Italian heart failure patients using structural equation modeling and simple slope analysis.

Results: Higher levels of self-care maintenance were associated with higher quality of life and lower hospitalization rates. Higher levels of comorbidity were associated with lower levels of self-care management. Comorbidity moderated the relationship between self-efficacy and self-care maintenance, but not self-care management. Post-hoc simple slopes analysis showed significantly different slope coefficients $\left(\mathrm{p}_{\mathrm{diff}}<.05\right)$. Specifically, in patients with less comorbidity, the relationship between self-efficacy and self-care was significantly stronger than in patients with higher comorbidity.

Conclusions: Self-efficacy is important in the self-care maintenance process at each level of comorbidity. Because higher comorbidity weakens the strength of the relationship between selfefficacy and self-care maintenance, tailoring interventions aimed at improving self-efficacy to different levels of comorbidity may be key to impacting hospitalization and quality of life. Keywords: comorbidity, self-efficacy, self-care, explanatory model 


\section{Introduction}

Comorbidity, defined as two or more chronic conditions, is associated with longer lengths of hospital stay, more hospital stays per year, and higher overall costs of care.(1,2) In Italy, where this study was conducted, approximately $50 \%$ of the general population between the ages of 65-74 has at least two chronic conditions.(3) This number jumps to $68 \%$ in heart failure populations (4) with hospitalization accounting for 53\% of the average costs.(5) It has been estimated that comorbidity is responsible for $70-80 \%$ of heath care costs in Europe or approximately 700 billion Euros in 2013.(2) In comorbid heart failure populations the need for concurrent adherence to multiple self-care regimens and management of overlapping symptom profiles is common.(6) Failures in self-care result in health system utilization and increased health care costs.(7)

Heart failure self-care is a 2 stage process.(8) First, self-care maintenance captures the day to day treatment adherence and monitoring behaviors. Then self-care management includes recognition of a change in homeostasis and response mobilization. The self-care process is influenced by self-efficacy.( $(8,9)$ Heart failure patients derive event-free survival benefits from above average self-care and decreased hospitalization rates and improved quality of life from adequate self-care (10-12) suggesting that the cost of heart failure may be mitigated by improving self-care.

However, recent attempts to decrease hospitalizations using self-care interventions have resulted in mixed outcomes.(13-16) In two, single site small RCTs, an in-person self-care intervention did not change readmission rates in the first study (15) and in the second, a technology intervention reduced 90 day hospital readmissions.(14) In a larger, multi-site three-arm RCT testing the impact of stepped self-care interventions on readmission, no significant differences were found when either intervention arm was compared with usual care.(13) Furthermore, a large meta-analysis of heart failure education and monitoring studies conducted in 10 countries found significant improvement in hospitalizations in 30 studies but also found a bias towards positive outcomes. (16) One possible explanation for this outcome heterogeneity may be the role of comorbidity in the 
study. In each of these studies comorbidity functioned, if measured, as a sample descriptor rather than an independent variable in multivariate analysis. So it is unclear what part, if any, comorbidity may have played in the response to the interventions. Our study seeks to clarify this important point.

In earlier work we established that there is interaction between comorbidity, self-efficacy and heart failure self-care in smaller samples. $(6,17)$ Specifically, we found that comorbidity decreases self-efficacy. Self-efficacy, in turn, decreases self-care behaviors. Yet the manner in which comorbidity and self-efficacy interact to influence self-care remains unclear. Building on this earlier work, our goal in this study was to create an explanatory model for the manner in which comorbidity, self-efficacy and heart failure self-care interact and test it structurally with meaningful outcomes - hospitalization and quality of life.

Therefore, the specific aim of this study was to test an explanatory model of known predictors of hospitalization and quality of life. The research questions were: 1) What is the contribution of comorbidity to heart failure self-care behaviors and outcomes (i.e. hospitalization, quality of life) adjusting for age and gender? and 2) Is comorbidity a moderator of the relationship between self-efficacy and heart failure self-care behaviors? Knowing the interaction among selfefficacy, comorbidity and self-care would clarify the mechanism by which hospitalization and quality of life are affected. This is important as self-efficacy is potentially modifiable and interventions designed to improve self-efficacy may differ when patients have different levels of comorbidity.

\section{Methods}

\section{Study design and setting}

This was a secondary analysis of a large cross-sectional database that described self-care in Italian heart failure patients.(18) In the parent study, a convenience sample of 1,192 adults with heart failure was enrolled from cardiovascular centres located across 28 provinces in northern, central, and southern Italy. Data were collected between January 2011 and November 2012. 
The inclusion criteria parent study were: 1) adults over age $18 ; 2$ ) diagnosis of heart failure by a cardiologist, confirmed by echocardiogram and clinical evidence of heart failure (e.g. typical signs and symptoms of heart failure such as edema or elevated jugular venous pressure and dyspnea) as specified in the diagnostic criteria of the European Society of Cardiology.(19) Individuals were excluded if they had experienced an acute coronary event in the prior three months or had a diagnosis of dementia.

For this analysis we selected only those heart failure patients who had experienced symptoms in the prior month $(\mathrm{n}=628)$ to allow us to analyze symptom management behaviors. While power analysis for structural equation modeling is difficult (20), using traditional power analysis software for 3 predictors where the squared multiple correlation is .25 and detection of a predictor that accounts for at least $5 \%$ unique variance in the outcome variable is desired; the required sample size to achieve .90 power is approximately 215 , signifying that we had a sufficient sample size to conduct this analysis.

\section{Ethical consideration}

The investigation confirmed to the principles outlined in the Declaration of Helsinki obtaining ethical review of all procedures prior to data collection in each center where patients were enrolled.

\section{Data Collection}

Data collectors were nurses who received at least 4 hours of training by the principal investigator on the study protocol. Training included: patient selection using inclusion/exclusion criteria, informed consent, instrument administration, and medical record abstraction for hospitalization data. Data were regularly monitored by the principal investigator for protocol adherence. Sociodemographic data (age, gender, education, marital status, job, family income), used to describe the sample, were collected using an investigator-developed survey instrument.

\section{Measures}

\section{Comorbidity}


Comorbidity was measured using the revised, 12 item Charlson Comorbidity Index (CCI).(21) Each item has a possible score of 1, 2, 3 or 6 . Heart failure is scored a 2 in this new version. Higher scores indicate higher comorbidity. The CCI is widely used in Italian studies with heart failure patients. $(22,23)$ Psychometric testing comparing the predictive ability of the revised vs. the gold standard original CCI found that it was comparable ( $C$ statistic range .73-.88). The CCI was completed by trained nursing research assistants abstracting information from patients' medical records.

\section{$\underline{\text { Self-Efficacy }}$}

Self-efficacy was measured using the self-care confidence scale of the Self-Care of Heart Failure Index (SCHFI V6.2).(24) The self-care confidence scale measures self-efficacy according to Bandura's conceptualization (25) that is, self-care confidence scale items describe capability and the scaling (1-4) provides the strength of the belief. Each of the 6 items asks about confidence in their ability to perform specific self-care maintenance and management behaviors (e.g., follow treatment regimen, manage symptoms). Measured on a four-point Likert scale, responses are summed and standardized to 0 - 100; higher scores indicate higher self-efficacy. Psychometric testing found that this scale is valid and reliable in the Italian population.(26) Specifically, confirmatory factor analysis showed a comparative fit index of 0.99 , and a root mean square error of approximation of 0.02 . Reliability tested with factor score determinacy, a more appropriate reliability testing for the SCHFI dimensionality, $(27,28)$ resulted with a coefficient of 0.82.(26) Self-care confidence is hereafter referred to as self-efficacy.(6)

\section{Self-Care Maintenance and Self-Care Management}

Heart failure self-care was measured using the SCHFI V6.2. The SCHFI is a well validated instrument that measures self-care maintenance (adherence to treatment regimens and symptom monitoring behaviors) with 10 items and self-care management (ability to recognize and respond appropriately to symptoms) with 6 items on a four-point Likert scale. Scores on the maintenance and management scales are standardized to $0-100$ score; higher scores indicate better self-care. A 
score of $\geq 70$ on each of the SCHFI scales is considered adequate.(24) Psychometric testing on the Italian heart failure population showed that the Italian version of the SCHFI is a valid and reliable tool to measure self-care maintenance and management.(26) Confirmatory factor analysis showed a comparative fit index of 0.92 and a root mean square error of approximation of 0.05 for the selfcare maintenance scale; a comparative fit index of 0.95 , and a root mean square error of approximation of 0.07 for the self-care management scale. Reliability of the two scales, estimated with the factor score determinacy, ranged between 0.78 and 0.90 . (26)

\section{$\underline{\text { Hospitalization }}$}

Hospitalization was measured as the number of admissions to an acute care facility due to heart failure in the last year. These data were collected from patients' medical records by research assistants using an investigator-developed survey instrument.

\section{Quality of life}

Quality of life was measured with the Minnesota Living with Heart Failure Questionnaire (MLHFQ), a 21-item instrument measuring the physical and emotional limitations experienced by patients as attributed to their heart failure.(29) Each MLHFQ item uses a 6-point Likert response format. The physical dimension score ranges from 0 to 40, the emotional dimension score ranges from 0 to 25 . Higher scores indicate worse quality of life. In order to make the interpretation of the two MLHFQ dimensions comparable, the physical and emotional dimension scores were standardized to $0-100$ and reversed with higher scores indicating better quality of life. The MLHFQ is widely used in Italian studies $(30,31)$ and its validity and reliability has been established $(32,33)$. Reliability of the MLHFQ in this study resulted with a Cronbach's alpha of 0.89 for the physical dimension, 0.86 for the emotional dimension and 0.92 for the whole instrument.

\section{Model Development}

Based on our earlier studies $(6,17)$ and an extensive review of the literature conducted by members of our group (34) we constructed a model a priori to test. The model represented the 
known relationships between the variables of interest - comorbidity, self-efficacy, self-care, hospitalization and quality of life. Heart failure experts were consulted to confirm structural validity before model testing (Figure 1).

\section{Data Analysis}

Data analysis was performed using SPSS 18.0 and MPlus 7.1. Descriptive statistics (mean, $\mathrm{SD}$, and frequencies) were used to describe the sociodemographic and clinical characteristics of the sample (e.g., gender, ejection fraction). Pearson's $r$ was used to analyze the correlation between comorbidity, self-efficacy, self-care, and outcomes (hospitalization and quality of life). Then data were analyzed with a structural equation model (SEM). A multiplicative term (comorbidity and self-efficacy) was created to examine the interaction effect. In order to reduce multicollinearity, comorbidity and self-efficacy were centered by subtracting the corresponding mean from the score of each variable.(35) Age and gender were covariates in the analysis. The following model fit indices were considered: omnibus fit indices such as the chi square $\left(\chi^{2}\right)$ and incremental fit indices such as the Comparative Fit Index (CFI), the Root Mean Square Error of Approximation (RMSEA), and the Weighted Root Mean Square Residual (WRMR). The following cut-off points were considered acceptable fit indices: CFI > 0.95 ; RMSEA $\leq .05$; WRMR $\leq 1.0 .(36,37)$

To better interpret the significant interactions between self-efficacy and comorbidity on selfcare maintenance and management, post-hoc simple slopes analysis and graphical representation were examined.(38) Specifically, we plotted the significant interaction effects for five levels of comorbidity, defining the very low level as two standard deviations below the mean; the low level as one standard deviation below the mean; the high level as plus one standard deviation above the mean; and the very high level as two standard deviation above the mean. This method permits plotting the relationship between self-efficacy and self-care behaviors (self-care maintenance and self-care management) for each level of comorbidity and testing whether each slope is significantly different from zero.

\section{Results}


Sample

Table 1 presents the sociodemographic, family and clinical characteristics of the total sample. The sample $(\mathrm{n}=628)$ was predominantly older $($ mean age $=72.98, \mathrm{SD}=11.34)$, male $(57.6 \%)$ and married (54.9\%). Patients had lived with heart failure more than 4 years on average and $75 \%$ of the sample was functionally compromised (NYHA classes II and III).

\section{Descriptive statistics (Table 2)}

Most $(75.6 \%)$ had at least one other comorbid condition in addition to heart failure $(\mathrm{CCI}=$ 2.98; $\mathrm{SD}=1.1)$. The most commonly reported comorbidities were atrial fibrillation $(44.5 \%)$, prior coronary events (40\%), COPD (38\%) and diabetes (36\%). The mean scores of self-efficacy was $53.93(\mathrm{SD}=20.55)$. Mean self-care maintenance and management were $54.99(\mathrm{SD}=15.70)$ and $53.18(S D=20.01)$ respectively. Based on the cut-off of $\geq 70$, only about the $20 \%$ of the sample performed adequate self-care. Most (73\%) of the sample had been hospitalized due to heart failure in the prior year. The mean length of hospital stay was $12.62(\mathrm{SD}=8.75)$ days. Physical and emotional quality of life were differentially affected by heart failure. Emotional quality of life scores were almost half of the physical quality of life scores ( 24 and 41.5 respectively using the reversed and standardized score).

\section{Bivariate relationships with outcome variables}

Table 3 shows the bivariate relationships between comorbidity, self-efficacy, self-care and outcomes. Hospitalizations were more frequent in patients with more comorbid conditions, lower self-care maintenance and worse physical and emotional quality of life. Better physical quality of life was associated with fewer comorbid conditions, better self-efficacy and better self-care maintenance. Better emotional quality of life was associated with fewer comorbid conditions and better self-care maintenance.

\section{Research Questions}

Research Question 1): The original model (Figure 1), when tested, fit the data poorly: $\chi^{2}(10)$ $=82.64, \mathrm{p}<.001 ; \mathrm{CFI}=.89 ; \mathrm{RMSEA}=.110(\mathrm{CI}=.089-.132), \mathrm{p}<.01 ; \mathrm{WRMR}=1.336$. 
Modification indices showed a significant direct effect of comorbidity on physical quality of life (higher comorbidity predicted lower physical quality of life) and hospitalization (higher comorbidity predicted more frequent hospitalizations) and a correlation between physical quality of life and hospitalization (higher physical quality of life was associated with fewer hospitalizations). These three modifications were supported by prior research.(39-41) The revised model with the three new parameters provided an excellent fit to the data: $\chi^{2}(9)=13.63, p=.14 ; \mathrm{CFI}=.99$; RMSEA $=.029(\mathrm{CI}=.000-.059), \mathrm{p}=.86 ; \mathrm{WRMR}=.496$. This model predicted $13 \%$ of the variance in hospitalizations, $9 \%$ of the variance in physical quality of life, and $5 \%$ of the variance in emotional quality of life.

As shown in Figure 2 higher levels of comorbidity were associated with lower levels of selfcare management. Higher levels of self-efficacy were associated with higher levels of self-care maintenance and self-care management. Higher self-care maintenance was associated with higher self-care management.

Research Question 2): In the moderation analysis, comorbidity moderated only the relation between self-efficacy and self-care maintenance. Higher self-care maintenance was associated with higher physical and emotional quality of life and fewer hospitalizations; higher self-care management was associated with lower emotional quality of life.

Post-hoc simple slopes analysis (Figure 3) showed significant differences among the slope coefficients (pdiff <.05). In patients with lower comorbidity the strength of the relationship between self-efficacy and self-care maintenance was stronger than in patients with higher comorbidity. In fact, as the level of comorbidity increased the relationship between self-efficacy and self-care maintenance decreased (from 0.55 in patients with the lowest comorbidity to 0.24 in patients with highest comorbidity). So, the strength of the relationship between self-efficacy and self-care was a function of comorbidity.

\section{Discussion}


The specific aim of this study was to test an explanatory model of known predictors of hospitalization and quality of life by identifying the contribution of comorbidity to heart failure selfcare and then testing comorbidity as a moderator of the relationship between self-efficacy and heart failure self-care behaviors. To our knowledge this is the first study describing the manner in which comorbidity, self-efficacy, and heart failure self-care interact to influence hospitalization and quality of life. In answer to our first question, comorbidity contributes significantly (directly and indirectly) to self-care behaviors and outcomes. In answer to our second question, the moderation hypothesis was supported in part when it was found that comorbidity moderates the relationship between self-efficacy and self-care maintenance but not self-care management. We also demonstrated that self-care maintenance was associated positively with both physical and emotional quality of life while negatively associated (directly and indirectly) with hospitalization.

The findings in this study support theoretical predictions (8) and prior work that selfefficacy is important in the self-care process. Self-efficacy has both a positive and a negative impact. That is, high self-efficacy is associated with better quality of life while low self-efficacy is a barrier to self-care. Previously, in a US sample we found that differentiating among symptoms is extremely difficult for patients.(17) Patients rarely integrate self-care instructions and ultimately prioritize their self-care based on the perceived threat and their experience with the particular condition. This finding suggested that the prioritization process may be influenced by the degree of self-efficacy felt in relation to a particular chronic condition.(17) Qualitatively, in a subsequent mixed methods study, we found that self-efficacy shaped how patients with comorbidity made selfcare maintenance and management decisions, particularly in maintaining dietary restrictions and making dietary choices, two key elements in treatment adherence.(6) Quantitatively, in that same study, there were statistically significant differences in self-care maintenance and management scores in groups with low vs. moderate or high comorbidity levels; with those with greater comorbidity scoring lower in self-care. In a moderation analysis comorbidity moderated the relationship between self-efficacy and self-care maintenance in the group with a moderate number 
(2-3) of chronic illnesses but not in the low comorbidity group (0-1 chronic illness). However, no moderator effect was found between self-efficacy and self-care management, which is consistent with the results reported here.

The findings of this study are supported by a recent German study where self-efficacy was identified as a determinant of heart failure self-care adherence.(9) Our study in an Italian sample adds to their results by recognizing that comorbidity complicates the day to day decisions about not just adherence but also symptom monitoring, both subdomains of self-care maintenance. In an earlier Canadian study significant associations were found between self-efficacy and self-care maintenance as well number of comorbidities and quality of life in bivariate analysis but in multivariate analysis this significance disappeared.(42) This result may have been a function of ignoring comorbidity as a moderator of self-efficacy. But taken together, the three earlier studies and our study, conducted in four different countries (two European, two North American), suggest that self-efficacy is universally important. Further testing of this hypothesis in different geographic areas is suggested.

However, focusing on increasing self-efficacy is not sufficient as the number of diseases increases or as a disease progresses. We found in the slope analysis that as the level of comorbidity increased the relationship between self-efficacy and self-care maintenance decreased, even though it remained statistically significant. Therefore, while there is a pressing need to develop interventions that increase patient self-efficacy early in the diagnosis; as the relationship between self-efficacy and self-care maintenance weakens this may no longer be sufficient to maintain the patient safely in a community setting. One potential option to mitigate the impact of comorbidity on the patient's self-care is to increase caregiver education and support as the patients' number of diseases increases or progresses. Nonetheless, we also need to understand the limitations of our current interventions and education protocols. In the presence of greater comorbidity, focusing on improving either patient or caregiver self-efficacy may be insufficient to assure improved outcomes such as patient quality of life, event free survival, or costs. Heart failure patients and families may need earlier 
referral to supportive or palliative care to manage the patient's comorbidity at home. Further study is needed on the effect of earlier referral before this can rise to the level of a recommendation. In the interim, clinicians would do well to consider the comorbidity burden of their patients and assess the impact on informal caregivers.

\section{Limitations}

This study involved a secondary analysis of existing cross sectional data from one particular country. Furthermore, we selected only symptomatic patients. This resulted in a sicker population who may have been further along in the trajectory of heart failure than commonly seen. However, given the common exclusion of this sicker population from large clinical trials, we feel that their inclusion is a strength of the study. Other strengths include the robust sample size $(n=628)$ and testing of a model developed from the literature and our previous work.(6) The current findings, in a unique population, support our earlier study.

\section{Implication for Research}

First, there is a need for rigorous, prospective, longitudinal, trials designed to specifically tease out the nuances in the relationships between comorbidity and heart failure self-care. To date all of the work has been done with existing cross sectional datasets. Second, there is the need to account for moderators in explaining the mechanism or meaningfulness of the relationships between variables. If heart failure researchers are not measuring comorbidity and accounting for it in analytic plans then we may be mis-specifying relationships among other variables and missing accurate explanations for the occurrence of certain relationships. Third, we have presented an explanatory model of the interaction of known predictors of hospitalization and quality of life with empirically verified parameters. However, while this model explained only $13 \%$ of the variance in hospitalization we achieved our aim which was to identify the contribution of comorbidity and its role as a moderator in self-care. We recommend that future studies include other variables and then repeat testing of the model to build the science. Fourth, we recommend that future interventional 
studies use our model as means to identify and target heart failure patients at higher risk for decreased quality of life or increased hospitalizations.

Conclusion

This study presented an explanatory model of variables known to be associated with hospitalization and quality of life in heart failure and identified the contribution of comorbidity. It was found that comorbidity differentially moderated the relationship between self-care self-efficacy and self-care maintenance but did not moderate the relationship with self-care management. Given what is known about comorbidity's association with longer lengths of hospital stay, more hospital stays per year, and higher overall costs of care; this model provides greater understanding of this relationship.

Funding: This work was supported by the Center of Excellence for Nursing Scholarship, Rome, Italy.

Conflict of Interest: none declared

Acknowledgement: The team of investigators would like to acknowledge Donna Fick, PhD, GCNS-BC, FGSA, FAAN; Distinguished Professor of Nursing and Professor of Medicine at Penn State for her careful review of this analysis and paper and her comments. 


\section{References}

1. Steiner CA, Friedman B. Hospital Utilization, Costs, and Mortality for Adults With Multiple Chronic Conditions, Nationwide Inpatient Sample, 2009. Preventing Chronic Disease. 2013;10:E62.

2. Rijken M, Struckmann V, Dyakova M, Melchiorre M, Rissanen S, van Ginneken E. ICARE4EU: Improving care for people with multiple chronic conditions in Europe. Eurohealthcare. 2013;19(3):29-31.

3. I.Stat: Italian National Institute for Statistics; 2015 [cited 2015 March 20]. Available from: http://dati.istat.it/Index.aspx?DataSetCode=DCCV MALCRON.

4. Cocchieri A, Riegel B, D'Agostino F, Rocco G, Fida R, Alvaro R, et al. Describing self-care in Italian adults with heart failure and identifying determinants of poor self-care. European Journal of Cardiovascular Nursing. 2013.

5. Valle R, Baccichetto R, Barro S, Calderan A, Carbonieri E, Chinellato M, et al. [Heart failure in Eastern Veneto: prevalence, hospitalization rate, adherence to guidelines and social costs]. Monaldi archives for chest disease = Archivio Monaldi per le malattie del torace / Fondazione clinica del lavoro, IRCCS [and] Istituto di clinica tisiologica e malattie apparato respiratorio, Universita di Napoli, Secondo ateneo. 2006;66(1):63-74.

6. Dickson VV, Buck, H., \& Riegel, B. Multiple Comorbid Conditions Challenge Heart Failure Self-Care by Decreasing Self-Efficacy. Nursing Research 2013;62(1):2-9.

7. Ditewig JB, Blok H, Havers J, van Veenendaal H. Effectiveness of self-management interventions on mortality, hospital readmissions, chronic heart failure hospitalization rate and quality of life in patients with chronic heart failure: A systematic review. Patient education and counseling. 2010;78(3):297-315.

8. Riegel B, Dickson VV. A situation-specific theory of heart failure self-care. Journal of Cardiovascular Nursing. 2008;23(3):190-6.

9. Peters-Klimm F, Freund T, Kunz C, Laux G, Frankenstein L, Müller-Tasch T, et al. Determinants of heart failure self-care behaviour in community-based patients: a cross-sectional study. European Journal of Cardiovascular Nursing. 2013;12(2):167-76.

10. Buck HG, Lee, C.S., Moser, D.K., Albert, N., Lennie, T., Bentley, B., Worrall-Carter, L., \& Riegel, B. . The Relationship between Self-care and Health Related Quality of Life in Older Adults with Moderate to Advanced Heart Failure. Journal of Cardiovascular Nursing. 2012;27(1):8-15.

11. Lee CS, Moser DK, Lennie TA, Riegel B. Event-free survival in adults with heart failure who engage in self-care management. Heart \& Lung: The Journal of Acute and Critical Care. 2011;40(1):12-20.

12. Vellone E, Chung ML, Cocchieri A, Rocco G, Alvaro R, Riegel B. Effects of Self-Care on Quality of Life in Adults with Heart Failure and Their Spousal Caregivers: Testing Dyadic Dynamics Using the Actor-Partner Interdependence Model. Journal of Family Nursing. 2014;20(1):120-41.

13. Dracup K, Moser DK, Pelter MM, Nesbitt T, Southard J, Paul SM, et al. A Randomized Controlled Trial to Improve Self-Care in Patients with Heart Failure Living in Rural Areas. Circulation. 2014.

14. Delaney C, Apostolidis B, Bartos S, Morrison H, Smith L, Fortinsky R. A Randomized Trial of Telemonitoring and Self-Care Education in Heart Failure Patients Following Home Care Discharge. Home Health Care Management \& Practice. 2013.

15. Davis KK, Mintzer M, Himmelfarb CR, Hayat MJ, Rotman S, Allen J. Targeted intervention improves knowledge but not self-care or readmissions in heart failure patients with mild cognitive impairment. European journal of heart failure. 2012.

16. Inglis SC, Clark RA, McAlister FA, Stewart S, Cleland JGF. Which components of heart failure programmes are effective? A systematic review and meta-analysis of the outcomes of structured telephone support or telemonitoring as the primary component of chronic heart failure management in 8323 patients: Abridged Cochrane Review. European Journal of Heart Failure. 2011;13(9):1028-40.

17. Dickson VV, Buck H, Riegel B. A Qualitative Meta-Analysis of Heart Failure Self-Care Practices Among Individuals With Multiple Comorbid Conditions. Journal of Cardiac Failure. 2011;17(5):413-9.

18. Cocchieri A, Riegel B, D'Agostino F, Rocco G, Fida R, Alvaro R, et al. Describing self-care in Italian adults with heart failure and identifying determinants of poor self-care. European journal of cardiovascular nursing : journal of the Working Group on Cardiovascular Nursing of the European Society of Cardiology. 2014. 
19. McMurray JJ, Adamopoulos S, Anker SD, Auricchio A, Bohm M, Dickstein K, et al. ESC guidelines for the diagnosis and treatment of acute and chronic heart failure 2012: The Task Force for the Diagnosis and Treatment of Acute and Chronic Heart Failure 2012 of the European Society of Cardiology. Developed in collaboration with the Heart Failure Association (HFA) of the ESC. Eur J Heart Fail. 2012;14(8):803-69. 20. Jaccard J, Wan CK. LISREL approaches to interaction effects in multiple regression: Sage; 1996. 21. Quan H, Li B, Couris CM, Fushimi K, Graham P, Hider P, et al. Updating and validating the Charlson comorbidity index and score for risk adjustment in hospital discharge abstracts using data from 6 countries. Am J Epidemiol. 2011;173(6):676-82.

22. Onder G, Pedone C, Landi F, Cesari M, Della Vedova C, Bernabei R, et al. Adverse drug reactions as cause of hospital admissions: results from the Italian Group of Pharmacoepidemiology in the Elderly (GIFA). Journal of the American Geriatrics Society. 2002;50(12):1962-8.

23. Testa G, Cacciatore F, Galizia G, Della-Morte D, Mazzella F, Russo S, et al. Charlson Comorbidity Index does not predict long-term mortality in elderly subjects with chronic heart failure. Age and ageing. 2009;38(6):734-40.

24. Riegel B, Lee C, Vaughan Dickson V, Carlson B. An update on the Self-Care of Heart Failure Index. J Cardiovasc Nurs. 2009;24(6):485-97.

25. Bandura A. Self-efficacy: The exercise of control: New York: Freeman; 1997.

26. Vellone E, Riegel B, Cocchieri A, Barbaranelli C, D'Agostino F, Antonetti G, et al. Psychometric properties of the self-care of heart failure index version 6.2. Res Nurs Health. 2013;36(5):500-11.

27. Barbaranelli C, Lee CS, Vellone E, Riegel B. Dimensionality and reliability of the self-care of heart failure index scales: further evidence from confirmatory factor analysis. Res Nurs Health. 2014;37(6):52437.

28. Barbaranelli C, Lee CS, Vellone E, Riegel B. The Problem With Cronbach's Alpha: Comment on Sijtsma and van der Ark (2015). Nurs Res. 2015;64(2):140-5.

29. Rector TS, Cohn JN. Assessment of patient outcome with the Minnesota Living with Heart Failure questionnaire: reliability and validity during a randomized, double-blind, placebo-controlled trial of pimobendan. Pimobendan Multicenter Research Group. American heart journal. 1992;124(4):1017-25.

30. Modica M, Ferratini M, Torri A, Oliva F, Martinelli L, De Maria R, et al. Quality of life and emotional distress early after left ventricular assist device implant: a mixed-method study. Artif Organs. 2015;39(3):220-7.

31. Giordano A, Scalvini S, Paganoni AM, Baraldo S, Frigerio M, Vittori C, et al. Home-based telesurveillance program in chronic heart failure: effects on clinical status and implications for 1-year prognosis. Telemed J E Health. 2013;19(8):605-12.

32. Munyombwe T, Hofer S, Fitzsimons D, Thompson DR, Lane D, Smith K, et al. An evaluation of the Minnesota Living with Heart Failure Questionnaire using Rasch analysis. Qual Life Res. 2014;23(6):1753-65.

33. Garin O, Ferrer M, Pont A, Wiklund I, Van Ganse E, Vilagut G, et al. Evidence on the global measurement model of the Minnesota Living with Heart Failure Questionnaire. Qual Life Res. 2013;22(10):2675-84.

34. Buck HG, Akbar JA, Zhang SJ, Bettger JAP. Measuring Comorbidity in Cardiovascular Research: A Systematic Review. Nursing Research and Practice. 2013;2013:11.

35. Cohen J. Statistical power analysis for the behavior sciences. 2nd ed. New Jersey: Lawrence Erlbaum; 1988.

36. Hoyle RH. Structural equation modeling: concepts, issues, and application. Thousands Oaks, CA Sage; 1995.

37. Tanaka JS. Multifaceted Conceptions of Fit. In: Kennet AB, Long JS, editors. Structural Equation Models. Newbury Park, CA: Sage; 1993. p. 10-39.

38. Cohen J, Cohen P, West SG, Aiken LS. Applied multiple regression/correlation analysis for the behavioral sciences. 3th ed. Hillsdale: Erlbaum; 2003.

39. Carlson B, Pozehl B, Hertzog M, Zimmerman L, Riegel B. Predictors of overall perceived health in patients with heart failure. J Cardiovasc Nurs. 2013;28(3):206-15. 
40. Chaudhry SI, McAvay G, Chen S, Whitson H, Newman AB, Krumholz HM, et al. Risk factors for hospital admission among older persons with newly diagnosed heart failure: findings from the Cardiovascular Health Study. J Am Coll Cardiol. 2013;61(6):635-42.

41. van Deursen VM, Urso R, Laroche C, Damman K, Dahlstrom U, Tavazzi L, et al. Co-morbidities in patients with heart failure: an analysis of the European Heart Failure Pilot Survey. Eur J Heart Fail. 2014;16(1):103-11.

42. Seto E, Leonard KJ, Cafazzo JA, Masino C, Barnsley J, Ross HJ. Self-care and Quality of Life of Heart Failure Patients at a Multidisciplinary Heart Function Clinic. Journal of Cardiovascular Nursing. 2011;26(5):377-85 10.1097/JCN.0b013e31820612b8. 


\section{What is already known about the topic?}

- Comorbidity is associated with longer lengths of hospital stay, more hospital stays per year, and higher overall costs of care

- Understanding the interplay of known antecedents of adequate heart failure self-care is necessary to begin to address rising hospitalization rates associated with comorbidity.

- In earlier work we established that there is interaction between comorbidity, selfefficacy and heart failure self-care

\section{What this paper adds.}

- An explanatory model of the interaction of known predictors of hospitalization and quality of life with empirically verified parameters

- Comorbidity moderates the relationship between self-efficacy and self-care maintenance but not self-care management

- As the level of comorbidity increased the relationship between self-efficacy and selfcare maintenance decreased 
Figure 1. The Theoretical Model guiding the study

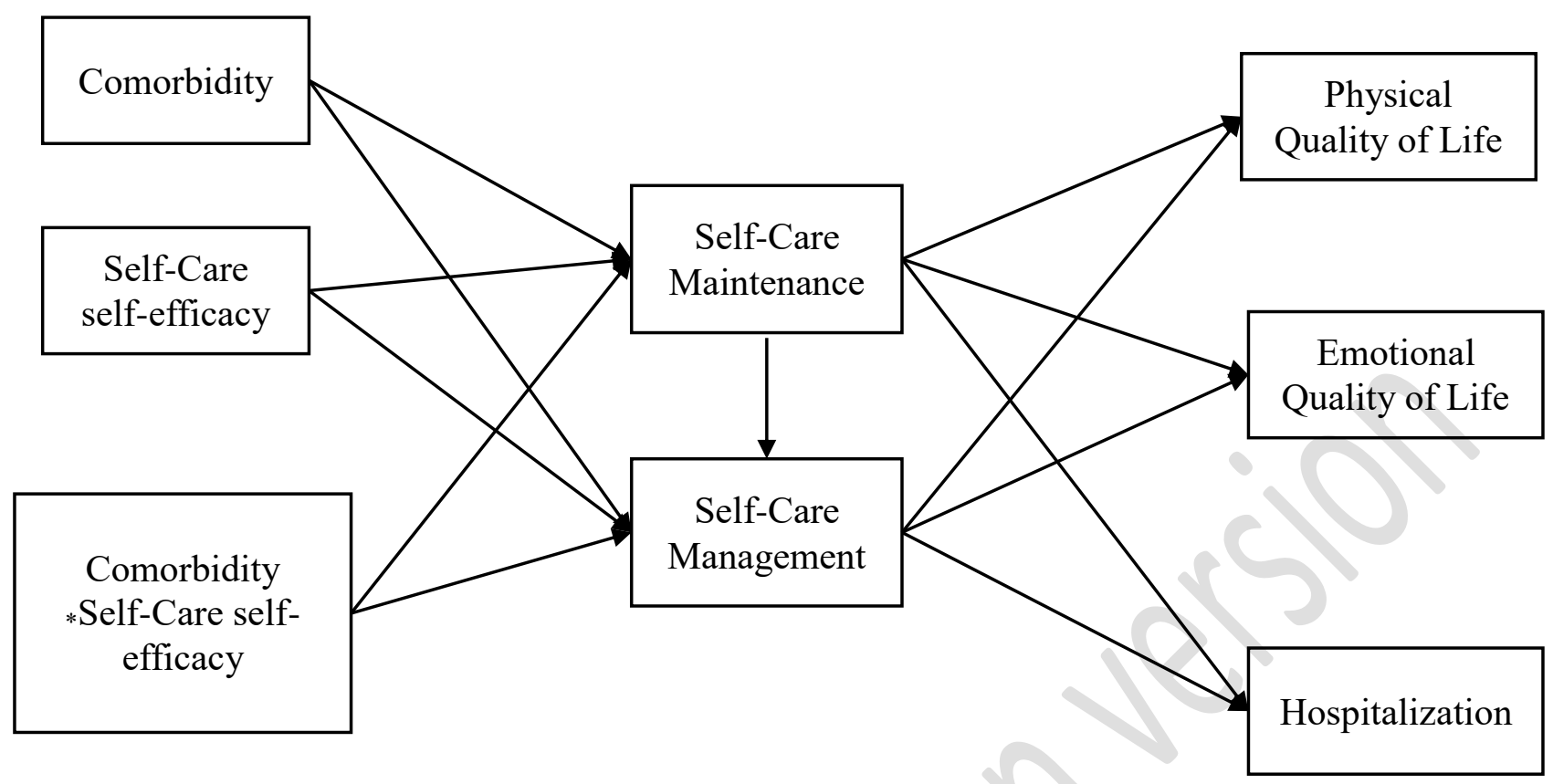


Figure 2. The Final Model

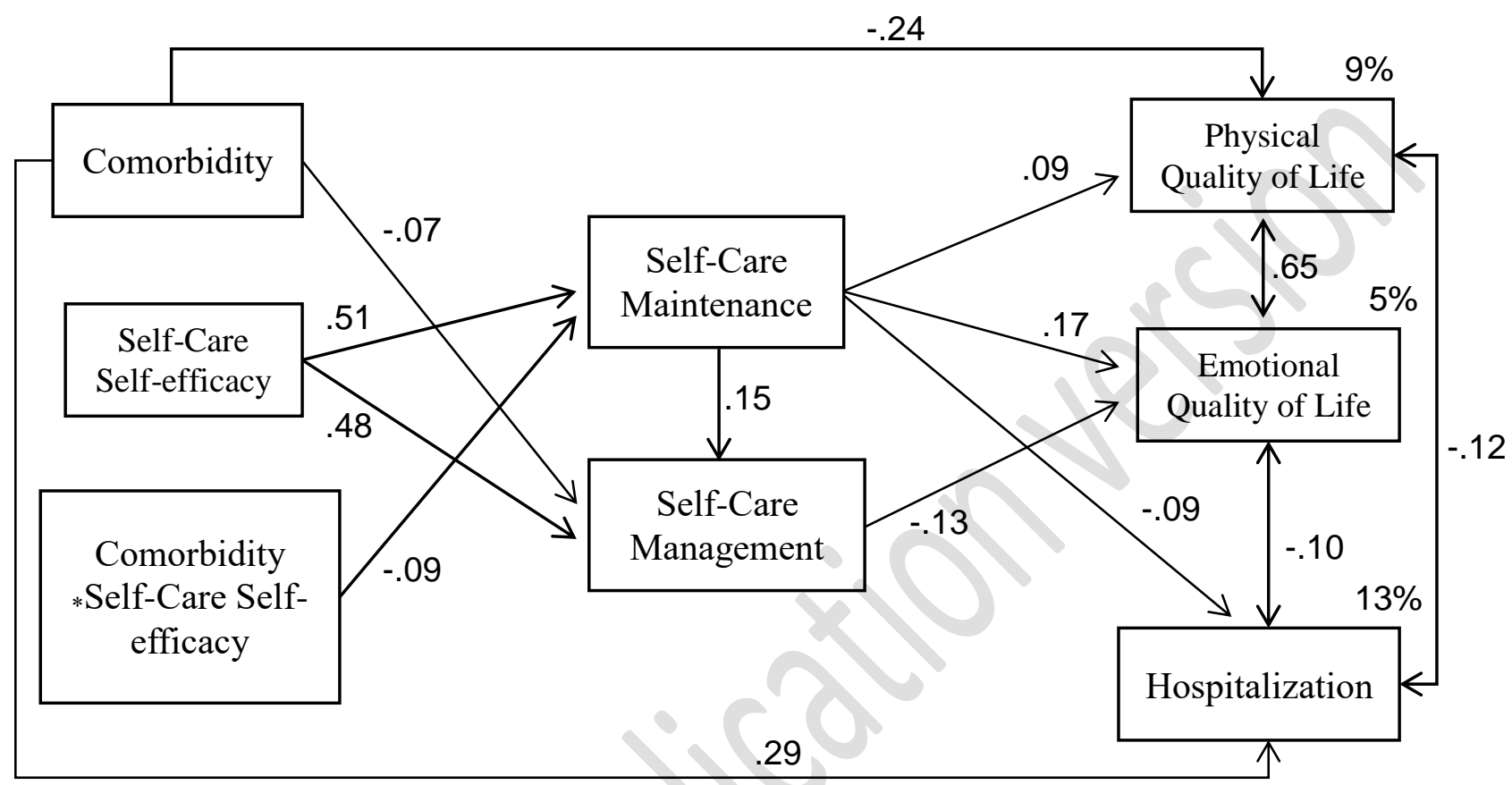

Note. The above model explained 9\% of the variance in Physical Quality of life; 5\% of the variance in Emotional Quality of life; and $13 \%$ of the variance in Hospitalization 
Figure 3. Moderation analysis

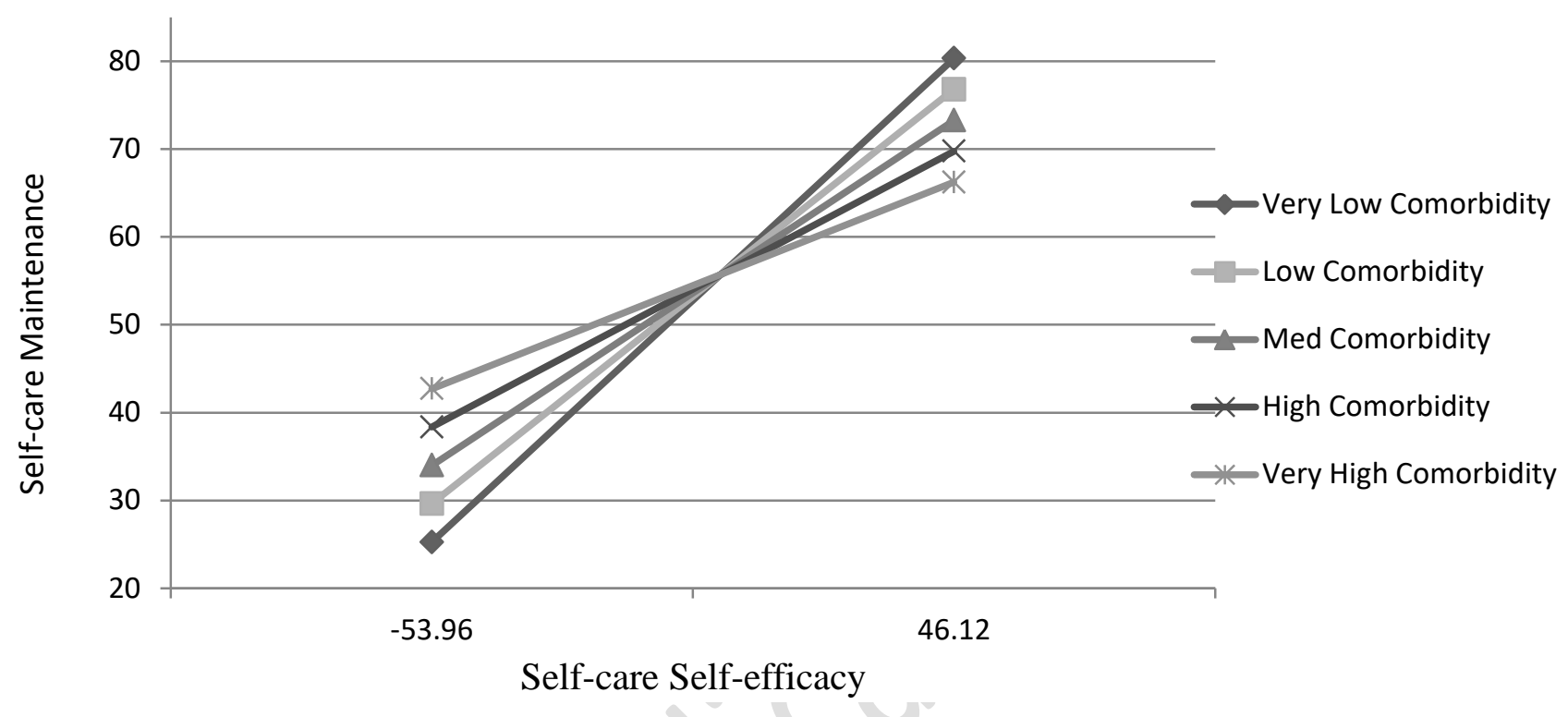

\begin{tabular}{lll}
\hline & $\begin{array}{l}\text { Comorbidity } \\
\text { levels }\end{array}$ & $\begin{array}{l}\text { Slope Coefficients between } \\
\text { Self-care Self-efficacy and } \\
\end{array}$ \\
& & Self-care Maintenance \\
\hline $\begin{array}{l}\text { Very Low } \\
\text { Comorbidity }\end{array}$ & -4.39 & $0.55^{* *}$ \\
Low Comorbidity & -2.20 & $0.47^{* *}$ \\
Med Comorbidity & 0 & $0.39^{* *}$ \\
High Comorbidity & 2.20 & $0.31^{* *}$ \\
Very High & 4.39 & $0.24^{* *}$ \\
Comorbidity & & \\
\hline
\end{tabular}

$* * \mathrm{p}<.001$

Note. This figure illustrates the relationship between Self-care Self-efficacy and Self-care Maintenance for different levels of comorbidity (very low, low, medium, high and very high comorbidity). For each effect the slope coefficient is provided 
Table 1 Socio-Demographic, Family and Clinical Characteristics of Patients $(\mathrm{N}=628)$

\begin{tabular}{|c|c|c|}
\hline Variables & $\mathrm{M}(\mathrm{SD})$ & $\mathrm{N}(\%)$ \\
\hline Age & $72.98(11.34)$ & \\
\hline \multicolumn{3}{|l|}{ Gender } \\
\hline Male & & $362(57.6)$ \\
\hline Female & & $266(42.4)$ \\
\hline \multicolumn{3}{|l|}{ Education } \\
\hline Elementary School & & $326(51.9)$ \\
\hline Middle School & & $152(24.2)$ \\
\hline Professional School & & $43(6.9)$ \\
\hline High School & & $74(11.7)$ \\
\hline University Degree & & $33(5.3)$ \\
\hline \multicolumn{3}{|l|}{ Marital Status } \\
\hline Married & & $245(54.9)$ \\
\hline Widowed & & $3(31.4)$ \\
\hline Single & & $49(7.8)$ \\
\hline Divorced & & $37(5.9)$ \\
\hline \multicolumn{3}{|l|}{ Job } \\
\hline Employed & & $542(86.3)$ \\
\hline Unemployed/Retired & & $86(13.7)$ \\
\hline \multicolumn{3}{|l|}{ Family income per month } \\
\hline \multicolumn{3}{|l|}{ (Euros, $n=606$ ) } \\
\hline $0-1000$ & & $209(34.5)$ \\
\hline $1001-2000$ & & $206(50.5)$ \\
\hline$>2000$ & & $91(15.0)$ \\
\hline Illness duration (months) & $55.95(45.6)$ & \\
\hline Ejection Fraction & $43.13(11.5)$ & \\
\hline \multicolumn{3}{|l|}{ NYHA class } \\
\hline 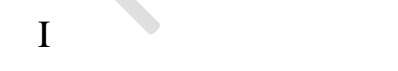 & & $56(8.9)$ \\
\hline II & & $231(36.8)$ \\
\hline III & & $263(41.8)$ \\
\hline IV & & $78(12.4)$ \\
\hline
\end{tabular}


Table 2. Comorbidities, HF Self-care Behaviors and Outcomes (N=628)

\begin{tabular}{|c|c|c|}
\hline Variables & $\mathrm{M}(\mathrm{SD})$ & $\mathrm{N}(\%)$ \\
\hline CCI score & $2.98(1.1)$ & \\
\hline \multicolumn{3}{|l|}{ Other Comorbidities } \\
\hline Atrial fibrillation & & $279(44.5)$ \\
\hline Prior Acute Coronary Syndrome & & $251(40.0)$ \\
\hline COPD & & $238(38.0)$ \\
\hline Diabetes & & $226(36.0)$ \\
\hline Anemia & & $141(23.7)$ \\
\hline Peripheral vascular disease & & $119(19.0)$ \\
\hline Renal disease & & $119(19.0)$ \\
\hline Sleep apnea & & $107(17.1)$ \\
\hline Peptic ulcer & & $75(11.9)$ \\
\hline Hemiplegia/Stroke & & $59(9.4)$ \\
\hline Liver disease & & $39(6.2)$ \\
\hline Cancer & & $40(6.4)$ \\
\hline Connective tissue disease & & $19(3.0)$ \\
\hline Leukemia & & $4(0.6)$ \\
\hline Lymphoma & & $2(0.3)$ \\
\hline \multicolumn{3}{|l|}{ Self-care behaviors } \\
\hline Self-care maintenance & $54.99(15.70)$ & \\
\hline Self-care management & $53.18(20.01)$ & \\
\hline Self-care confidence (self- & $53.93(20.55)$ & \\
\hline \multicolumn{3}{|l|}{ efficacy) } \\
\hline \multicolumn{3}{|l|}{ MLHFQ } \\
\hline Physical dimension & $41.5(21.2)$ & \\
\hline Emotional dimension & $24.0(12.0)$ & \\
\hline \multicolumn{3}{|l|}{ Hospitalization in last year } \\
\hline Never hospitalized & & $232(26.9)$ \\
\hline Hospitalized once & & $252(40.1)$ \\
\hline Hospitalized twice & & $98(15.6)$ \\
\hline Hospitalized $\geq 3$ times & & $46(7.3)$ \\
\hline
\end{tabular}

Note. $\mathrm{CCI}=$ Charlson Comorbidity Index; COPD = Chronic Obstructive Pulmonary Disease;

MLHFQ = Minnesota Living with Heart Failure Questionnaire; MLHFQ scores have been reversed (higher score $=$ better QOL) and standardized on $0-100$ range; patients could have more than one illness. 
Table 3. Bivariate relationships among Comorbidity, Self-efficacy, Self-care and Outcomes

\begin{tabular}{lccccccc}
\hline & 1 & 2 & 3 & 4 & 5 & 6 & 7 \\
\hline 1. CCI & 1 & & & & & & \\
2. Self-care self-efficacy & -.071 & 1 & & & & & \\
3. Self-care maintenance & -.066 & $.512^{* *}$ & 1 & & & & \\
4. Self-care management & $-.114^{* *}$ & $.579^{* *}$ & $.406^{* *}$ & 1 & & & \\
5. MLHFQ-P & $-.257^{* *}$ & $.088^{*}$ & $.107^{* *}$ & .074 & 1 & & \\
6. MLHFQ-E & $-.163^{* *}$ & .024 & $.112^{* *}$ & -.039 & $.638^{* *}$ & 1 & \\
7. Number of hospitalizations & $.211^{* *}$ & $-.157^{* *}$ & $-.177^{* *}$ & -.066 & $-.180^{* *}$ & $-.110^{* *}$ & 1 \\
\hline
\end{tabular}

Note. CCI = Charlson Comorbidity Index; MLHFQ-P = Minnesota Living with Heart Failure Questionnaire Physical Dimension; MLHFQ-E = Minnesota Living with Heart Failure Questionnaire Emotional Dimension. The scores of the MLHFQ-P and MLHFQ-E have been reversed with higher scores meaning better quality of life; $*=p<0.05 ; * *=p<0.01$. 